\title{
The Information Needs of Individuals Affected by Harmful Gambling in Ireland
}

Crystal Fulton, University College Dublin, Ireland

\begin{abstract}
Harmful gambling is an addiction issue that negatively affects not only gambling participants but also their families and friends. Ireland is estimated to be one of the top countries in the world for levels of gambling; however, legislation and social policy lag behind measures in other countries. This paper reports findings related to information seeking and provision from the first national study of the social impact of harmful gambling in Ireland. In-depth interviews were conducted with addiction counsellors, recovering gamblers, and gamblers' social connections to explore their perceptions of availability of information and services to address this public health issue. In addition to calling for revised regulatory and policy development to support formal channels of information and service provision to facilitate individual recovery, participants believed initiatives around providing information and educating the public about the potential personal and social risks associated with gambling would help protect those vulnerable to harm from gambling. Critically, participants identified a need for information to facilitate well-being as central to addressing this issue.
\end{abstract}

Keywords: gambling addiction; harmful gambling; health behaviour, health information; information-seeking behaviour

Publication Type: research article

\section{Introduction}

$\mathrm{H}$ armful gambling is a socially disruptive problem in many regions, frequently leading to financial crises, broken relationships, and even suicide; however, there is little research generally around the social impact of harmful gambling, for example, on families (Kourgiantakis, Saint-Jacques, \& Tremblay, 2013). Instead, research has most often focused on the gambler with a problem. As a country widely known for gambling, Ireland offers a unique area for study because of the lack of regulation and social policy around harmful gambling, in spite of its widespread social impact. This paper reports findings related to information seeking and provision from the first national study of social impact of harmful gambling in Ireland, in particular, exploring stakeholders' perceptions of the availability of information and services and the need for particular information initiatives to address this public health issue.

\section{Gambling in Ireland}

Ireland offers a special case for exploration of information in risky situations. Harmful gambling is widely perceived as a public health issue in the country, but regulation lags behind that of other countries, leaving the industry largely open to conduct business unchallenged. Importantly, 
while the Economist recently ranked Ireland as the third highest country in the world for gambling (Data Team, 2017), the number of people affected by harmful gambling has been to-date uncounted in Ireland. The Department of Health (2018) in Northern Ireland published the Republic's first data about the frequency and extent of gambling released on February $27^{\text {th }}, 2019$; it is unknown why these data, collected in 2014-2015, were only published and then released by government just recently. It should be noted that the data cover some of the data and analyses usually covered by a full prevalence study; these data were part of a study that mainly reviewed drug use. Calado and Griffiths (2016) underscored the need for prevalence research about gambling in the country, identifying Ireland as one of 21 European countries that had previously not conducted adult prevalence studies of gambling. The lack of information about gambling and resulting harm in Ireland has increased difficulty with understanding and addressing the need for information and services around this form of addiction.

This gap in information about gambling in Ireland has meant that the prevalence studies of other countries, namely Northern Ireland and the United Kingdom (UK), have often been used to estimate numbers of gamblers who are at-risk or addicted in Ireland (e.g., Institute of Public Health in Ireland, 2010). For instance, Wardle et al. (2011) reported that, in Britain, $1.2 \%$ of the population are affected by harmful gambling, with an additional $4.2 \%$ at risk of a problem. In Northern Ireland, 2.3\% have been classified as problem gamblers (Dunne, Flynn, \& Sholdis, 2017) compared to $2.6 \%$ in a 2010 survey (Analytical Services Unit, 2010). In addition, $4.9 \%$ of gamblers have been categorised as at moderate risk in Northern Ireland (down from 5.9\% in 2010) and 6.7\% at low risk of a problem (down from 8.2\% in 2010) (Dunne et al., 2017; Analytical Services Unit, 2010). Instances of harmful gambling in Northern Ireland are mostly higher than in other countries that have done a prevalence study, with higher figures only for Hong Kong and South Africa (Dunne et al., 2017). Numerical analyses may also differ from jurisdiction to jurisdiction, with varying outcomes in estimates of the number of individuals at risk or with gambling addiction, for example, the exclusion of National Lottery results from calculations (Wardle et al., 2010).

In the absence of any formal assessment of gambling prevalence until now, some addiction service providers in the Republic of Ireland offered their own evaluation of the extent of gambling in the country using their programme intake as an indicative estimation of the growth of gambling harm. For instance, Aiséirí collected data about the numbers of clients seeking assistance with gambling addiction, noting an increase during their 2011-2013 data collection window (Mullins, 2014). The Rutland Centre, a major addiction treatment facility in Dublin, has estimated that the number of people requesting help with gambling addiction has tripled, rising from $3 \%$ of clients in 2013 to nearly 10\% of clients in 2015 (Brennan, 2016).

The newly published data about gambling in the Republic of Ireland provided self-reported information from the public, which can have issues as acknowledged in the report (Department of Health, 2018). Key findings included several statistics around the extent of gambling among age groups and by gender. The study found that problem gambling was most prevalent in young males, with $2.9 \%$ of males aged 25 to 34 and $1.9 \%$ of males aged 18 to 24 . "Gambling online or by telephone" was most prevalent among 25 - to 34-year-olds $(5.7 \%)$ and 18 - to 24 -year-olds (4.8\%) (Department of Health, 2018). Respondents aged 55 to 64 were most likely to say they gambled in the previous year (72.4\%), though 35- to 44-year-olds came a close second at $70.5 \%$, and 45- to 54-year-olds were right behind at 69.4\% (Department of Health, 2018). Study outcomes focussed on underage gambling revealed that one in ten 15- to 17-year-olds reported buying lottery tickets or scratch cards in the previous year and $9.4 \%$ of respondents in this age bracket placed bets on horse or dog races, despite the fact that the legal age for gambling in Ireland is

The International Journal of Information, Diversity, \& Inclusion, 3(3), 2019

ISSN 2574-3430, jps. library.utoronto.ca/index.php/ijidi/index

DOI: $10.33137 /$ ijidi.v3i3.32962 
18 years (Department of Health, 2018). By comparison, the 2015 European School Survey Project (Molinaro et al., 2018) reported $22.6 \%$ of 16 -year-olds in Europe gambled in the previous year, with $16.2 \%$ gambling online and $18.5 \%$ gambling offline.

Findings by gender revealed that men under 65 years of age were more likely to say they gambled in the previous year than women; however, women outnumbered men in particular gambling activities, such as lottery tickets and scratch cards, where $62.6 \%$ of women aged over 65 engaged in this activity versus just $55.0 \%$ of men (Department of Health, 2018). Male gamblers aged 18 to 34 were more likely than other men of other ages or women of all ages to gamble online or by telephone. Additionally, more women reported playing bingo than men; women aged 18 to 24 formed the highest number of bingo players in the previous year (10.1\%) (Department of Health, 2018). Ronzitti, Soldini, Lutri, Smith, Clerici, and Bowden-Jones (2016) found that the form of gambling was linked to gambling severity in the UK; they concluded that some forms of gambling, such as fixed odds betting terminals (FOBTs) could be more addictive that other forms of gambling, especially when used regularly, and that overall play patterns, rather than focussing on certain types of gambling, should be considered when predicting risk for gambling addiction. Castren, Perhoniemi, Kontto, Alho, and Salonen (2017) similarly found that gambling harm in Finland was associated with particular games that enable more frequent gambling; the authors recommended that legislative and public health measures around specific games should be implemented to mitigate harm. Importantly, gender may play a role in gambling harm; Svensson and Romild (2014) found that men and women also participate in different gambling activities in Sweden. These authors further reported that women who gamble regularly may be more prone to harm than men, in spite of women gambling less than men.

The other interesting finding was the prevalence of gambling among socio-economic groupings, which was highest among middle management senior civil servants, managers and business owners (71.4\%), and lowest among semi-skilled and unskilled manual workers, trainees and apprentices (60.4\%) (Department of Health, 2018). Those categorised as dependent on the state long term had the lowest prevalence for gambling online or by telephone $(1.5 \%)$, betting on horse or dog races $(8.1 \%)$, betting at casinos $(1.7 \%)$, and playing cards for money with family or friends (4.5\%); however, this group showed the highest prevalence for playing bingo in person (4.6\%) (Department of Health, 2018). Future prevalence data collection would enable comparative analyses in Ireland, including information on the growth of gambling.

The legal framework around gambling in Ireland is complex, with multiple statutes covering aspects of gambling. The gambling industry is split into two areas of legislation: that governing the National Lottery (National Lottery Act 2013) and that covering other parts of the gambling industry (Betting Act 1931; Gaming and Lotteries Act 1956). Within this existing legislation, social responsibility, including a commitment to addiction treatment and prevention, has not been not addressed; the Gambling Control Bill: General Scheme, 2013 offered to address this gap; however, this framework for legislation did not move to bill stage. A private member's bill, the Gambling Control Bill 2018, passed second stage of government review, and then was shelved as well. Legislative efforts appear to have focused on the Betting (Amendment) Act of 2015, which updated the Betting Act of 1931, including new clauses around online betting. As of the time of preparing this article, there has been no further act or bill put forward to revise existing legislation around gambling in Ireland, meaning that there is no regulation around a social fund nor emerging digital technologies.

Other countries vary in their approach to governance of gambling. In North America, gambling is

The International Journal of Information, Diversity, \& Inclusion, 3(3), 2019

ISSN 2574-3430, jps. library.utoronto.ca/index.php/ijidi/index

DOI: $10.33137 /$ ijidi.v3i3.32962 
regulated regionally as opposed to by national government; by province in Canada and by state in the U.S. Australia regulates gambling at territory and state levels. The UK's Gambling Commission monitors all gambling, with local authorities and Scottish Licensing Boards also exercising control. The European Union (EU) court provides for member states to regulate gaming activities in their jurisdiction (Verbiest \& Keuleers, 2003). Additionally, with the advent of online gambling, the EU Commission has recommended principles for member states to use in regulations, such as advertising, social responsibility, and information and online support to help gamblers understand risk (European Commission, 2014).

\section{The Social Impact of Harmful Gambling}

The actual extent of social impact is much wider than that experienced by gamblers alone. Harmful gambling affects not only the individual who gambles, but also their families and friends. Gambling addiction frequently leads to depleted finances and broken relationships and is associated with feelings of shame and stigma, depression, and sometimes self-harming. Stories of high-profile Irish gamblers highlight additional community impact where gamblers have stolen large amounts of money from employers or have committed crimes or socially questionable acts (e.g., Lynch \& O’Reilly, 2018).

Although the social impact of harmful gambling can be significant and widespread, harmful gambling is not classified as a public health issue by official health entities, such as the World Health Organisation. In Ireland, national health policies only address drugs and alcohol; while gambling is sometimes mentioned, it is not the focus of policies. The lack of formal information about gambling harm emanating from government has created an information vacuum in the country. No single government body or organisation has an overview of addiction services or other information services. The complex needs resulting from gambling addiction can range from financial services to counselling; there is no body in Ireland with an overview of services available to those affected by harmful gambling. Even the country's current longitudinal Growing Up in Ireland project (Economic \& Social Research Institute, 2016), which surveys members of the population over a period of years about a range of everyday topics, such as smoking, drugs, and alcohol, does not probe into gambling.

\section{Services and Information Provision About Harmful Gambling}

The secrecy surrounding harmful gambling, both among affected gamblers and family members, challenges service and information provision. Treatment for gambling addiction often focuses on cognitive therapies. Additionally, the Minnesota Model, a patient-centred programme developed to address alcohol addiction in the 1950s (Anderson et al., 1999), is often applied to gambling addiction. This model follows a 12-step recovery approach, calling for family involvement, abstinence, education, individualised treatment plans, and aftercare (Anderson, 1999), and this programme generally forms the basis of treatment in Irish gambling addiction services. Gamblers Anonymous, a fellowship-based group known throughout the world, often works with addiction centres to facilitate recovery.

Addiction counselling services exist throughout Ireland, from centres to sole counsellors, and often treating multiple addictions. In the case of harmful gambling, the focus of treatment is very often the gambler. Services to families affected by harmful gambling are far less common. Gam-Anon, the counterpart to Gamblers Anonymous, provides fellowship for families. Notably, the RISE Foundation is one of a very few services in Ireland that provides counselling to families

The International Journal of Information, Diversity, \& Inclusion, 3(3), 2019

ISSN 2574-3430, jps.library.utoronto.ca/index.php/ijidi/index

DOI: $10.33137 /$ ijidi.v3i3.32962 
affected by a range of addictions, including gambling. There are also multiple social services for the problems associated with harm from gambling, including suicide prevention, the Money Advice and Budgeting Service (MABS), the Citizen's Advice Bureau which offers a range of social and legal information, and general charitable and religious organisations. Addiction services may include these types of social services in a gambler's recovery plan.

Information referral may occur through health practitioners. There are also information referral services run through gambling organisations, and these send callers from the Republic of Ireland to selected addiction centres in the Republic for assistance, including Dunlewey Addiction Services in Belfast, Northern Ireland, which is funded by the Irish Bookmakers Association, and Betfair's call centre in the UK.

\section{Method}

\section{Research Objective and Questions}

This research was exploratory in nature, since no previous national study of the social impact of harmful gambling has been conducted in Ireland. The objective of this research was to examine the social impact of gambling in the country, uniquely from the perspectives of the many stakeholders in the social outcomes of harmful gambling: namely, gamblers, their families and friends, and the addiction counsellors who assist those affected by harmful gambling. The part of the project reported in this paper explored the following research questions relevant to health and information concerns around harmful gambling:

- When did participants decide to seek or not seek help with the effects of harmful gambling?

- How did participants acquire and use information and services to ameliorate the effects of harmful gambling?

- What social structures, including policies and information provision, did participants identify as necessary to reduce the potential for harm through gambling?

\section{Research Approaches: Ethnographic Site Visits and In-depth Interviews}

Two methodological strategies enabled deep information gathering. First, an in-depth interview approach with individual participants provided all three stakeholder groups with an opportunity to share their experiences and to give their perspectives on the social impact of harmful gambling in detail. In-depth interviews are normally intensive interviews with a small number of people, intended to probe more deeply about issues than other research approaches (Boyce \& Neale, 2006). As Guest, Namey, and Mitchell (2013) described, in-depth interviews are "almost always, in part or in whole, about how and why, helping researchers to understand their interviewees' views of processes, norms, decision-making, belief systems, mental models, interpretations, motivations, expectations, hopes, and fears" (p. 8).

Alongside this approach, ethnographic visits to addiction treatment centres helped to contextualise the process of recovery and the availability of resources to support individuals who have been affected by harmful gambling. As part of the process of conducting an interview with an addiction counsellor on site, for instance, at a residential addiction centre, the researcher

The International Journal of Information, Diversity, \& Inclusion, 3(3), 2019

ISSN 2574-3430, jps.library.utoronto.ca/index.php/ijidi/index

DOI: $10.33137 /$ ijidi.v3i3.32962 
was able to tour facilities with the addiction counsellor. Visiting facilities allowed the researcher to spend time in the recovery environment with the staff and clients, evidencing recovery programme activities and interactions.

\section{Participants}

Three central stakeholder groups participated in in-depth interviews: addiction counsellors, recovering gamblers, and gamblers' social connections. Participants were located through snowball sampling, in which participants refer the study to other potential participants (see e.g., Atkinson \& Flint, 2001; Lewis-Beck, Bryman \& Liao, 2004).

Addiction counsellors. Addiction counsellors from ten addiction services spread throughout the country participated in interviews. Addiction counsellors were key stakeholders due to their expert knowledge on how gambling addiction affects gamblers and their families, and the treatment of this condition. Addiction counsellors were inclusive of volunteer and not-for-profit groups and for-profit enterprises. They were divided between women (40\%) and men $(60 \%)$. Positions held by participants ranged as follows: $50 \%$ were directors or managers of an addiction service; $40 \%$ were counsellors; and 10\% were psychologists. Approximately one half of participants reported working with people affected by gambling for 10 or fewer years; the other half had worked with people affected by gambling for 16 to 30 years.

Recovering gamblers and social connections. A poster placed with addiction counsellors, alongside advertising through press releases and social media, facilitated a snowball approach in locating gamblers and their social connections for the next stage of interviewing. A total of 22 matched pairs of recovering gamblers and their families and friends participated in in-depth interviews. Harmful gambling is a socially isolating activity, and where a gambler's familial relationships were broken, the gambler nominated a friend for interview.

Recovering gamblers were mainly male (19 in total, $86 \%$ of participants) and three $(14 \%)$ were female, reflecting the composition of those in recovery, though addiction counsellors spoke of increases in women and young people experiencing gambling harm. Family and friends were mixed in terms of gender. Nearly one half were partners, almost one quarter were parents, and the remainder were spread among siblings, children, and friends.

\section{Research Ethics}

Fulton's Research Ethics Committee has assigned the following Research Ethic Reference Numbers (RERN) to the project phases as follows:

- Addiction counsellors: Research Ethics Exemption Reference Number (REERN): HS-E-13105-Fulton, C.

- Gamblers and their social connections: HS-13-63-Fulton, C., and HS-13-63-Fulton, C.

All participants received a Letter of Information and signed a Letter of Consent to provide informed consent to participate. All volunteers for participation were aged 18 or older.

\section{Data Analysis}

Interview data and site visit notes were coded using line-by-line coding and a constant

The International Journal of Information, Diversity, \& Inclusion, 3(3), 2019

ISSN 2574-3430, jps. library.utoronto.ca/index.php/ijidi/index

DOI: $10.33137 /$ ijidi.v3i3.32962 
comparative approach. The constant comparative approach, developed by Glaser and Strauss (1967), involves a process of continuous data collection, analysis, and coding of data, through which theory may emerge. Kolb (2012) has observed that "The benefit of using this method is that the research begins with raw data; through constant comparisons a substantive theory will emerge" (p. 83). Data for this project were continuously reviewed throughout data collection and analysis for patterns in information behaviour among recovering gamblers and their family members and friends, resulting in a body of information about how these individuals behave and interact in stressful situations with risk to well-being and their perceptions of how information can help. NVivo's qualitative analysis software facilitated examination of the data for patterns among participant responses.

\section{Findings}

\section{Decision-Making Around Seeking Help}

Recovering gamblers accessed information and specific help through addiction counselling, both as residential addiction services and one-to-one counselling services, found through their family doctor, private counsellors, and the national health care system. Addiction services facilitated connections with other services. Among these, Gamblers Anonymous played a significant role in treatment and offered long-term fellowship for the gambler which continued after counselling.

The outcomes of experiencing harm from gambling created a wide range of complex information needs for gamblers and their families around issues such as lost finances, relationship breakdown, and health impairment because of stress. Addiction counsellors observed that by the time an individual sought help, that person and their family were most often in crisis, including emotional, financial, and sometimes legal difficulty. As a result, not only did people have multiple information needs, those needs were frequently acute.

While gamblers reported seeking help when they could no longer sustain their gambling and conceal the gambling and the attending problems caused by gambling, family members spoke of varied points when they decided to seek help, as well as reasons for asking for help. Among those who decided to seek help, some family members said they sought help immediately upon discovering the problem. One parent noted a range of reasons for seeking help: "Just the fact that I could see it was going to be a problem, and the fact that he was underage. And clearly teenagers don't make good decisions most of the time."

However, others, such as partners, needed time to process the shock of discovery of the problem; one wife explained: "Probably a few months, yes, I would say it was a couple of months when I got my own head around it and then I said right, ok, maybe I just need to see what is going on."

Other family members sought assistance from gambling support groups and sometimes other family members, working in conjunction to try to help the gambler. Often the circle of those asked for help was quite small, because family members sometimes felt the help they needed did not exist; for instance, one family member noted: "Well, I asked my father, but other than that, I didn't, because there was none to help. The help I needed was financial and who was going to do that?"

Another family member spoke of the emotional and financial aloneness in dealing with the aftermath of her partner's gambling addiction:

The International Journal of Information, Diversity, \& Inclusion, 3(3), 2019

ISSN 2574-3430, jps.library.utoronto.ca/index.php/ijidi/index

DOI: $10.33137 /$ ijidi.v3i3.32962 
There was nothing there, and I desperately needed help in that I had the three children. I had the financial thing. He had just cut himself off. He had this problem. He was focussing on recovery. I was dealing with all this.

The weight of problems resulting from harmful gambling on family was deepened by the feeling that they were on their own without assistance. In some cases, family members did not necessarily seek or access help. They cited many reasons for not seeking help, including placing responsibility for help-seeking with the gambler, not believing they needed counselling, and that seeking help was impossible because of the lack of services or lack of financial resources. Shame and stigma played key roles in decision-making around asking for help, not only for recovering gamblers, but also for their families. As one family member noted, she did not seek help because she did not want people to know there was a problem: "Because I didn't want the lads to find out. I didn't want [my daughter] to find out... And, I just feel, if you tell one person, someone else will tell someone else, and it will get out."

Free help was sometimes available through Gam-Anon, the sister organisation of Gamblers Anonymous, for families harmed by gamblers' addiction. One family member reported that they took the initiative to set up a branch of Gam-Anon in their region to support themselves and others, since assistance to families was lacking. Another family member noted that "HSE [Health Services Executive]-provided services were abysmally lacking." Instead, this participant commended Gam-Anon and Hope House, a residential addiction centre, as "the cornerstone of our recovery. The combination for us was the cornerstone we both needed."

\section{Acquisition and use of information and services}

When individuals did seek help, they found that information was not accessible in one place, and that the information and help needed did not necessarily exist. Families also reported that they participated in residential programmes as part of the gambler's recovery and observed that services dedicated to families were needed. As one family member noted: "There is terrible support for families. And I think it is the families that are left to pick up the pieces."

Recovering gamblers often reported that they attended addiction services focused widely on multiple addictions; very few services targeted young people and women who experience gambling harm, or family who have experienced harm from a loved one's addiction. Accessing information as an individual looking for support was also difficult; as one family member explained:

[What is needed is] not workbooks but a package, an education pack to help me, if I had a son or daughter who was a compulsive gambler. That there was some sort of information pack to help me to approach them or strategies I could use to help them. And then, obviously, within the family unit itself, getting down to the micro level, to say you shouldn't be afraid to talk about it.

Access to information was further inhibited by the extended impact of harmful gambling on social relationships, beyond one's immediate family, to communities. Harmful gambling isolated the gambler, as well as their families, from immediate and extended family and the wider social circle of the community. Social ties were often completely broken. As a friend of one gambler observed, the gambler lost not only their friends, but also their community status. Because gambling is socially embedded, friends did not necessarily understand the harm experienced by

The International Journal of Information, Diversity, \& Inclusion, 3(3), 2019

ISSN 2574-3430, jps.library.utoronto.ca/index.php/ijidi/index

DOI: $10.33137 /$ ijidi.v3i3.32962 
gamblers and their families, nor the recovery process.

The complexity of the outcomes of harmful gambling meant that addiction counsellors often found themselves functioning in multiple roles to assist people. In addition to counselling individuals and groups, addiction counsellors might find themselves offering a range of advice applicable to daily life, such as legal or financial advice. For example, one addiction counsellor described her role as being holistic, including supports as needed in a given gambling case. This participant provided an example of a case where they worked with the family regarding money issues:

Last week, I had to meet with somebody and find out where [Organisation] was in their area, because they don't even have food in their fridge [to feed] the kids. No money, no money at all, because of the gambling. People come to the door and the wife doesn't know if what he-because he can't remember who he owes money toand when they come, she will actually take the food money and give it to them, because she feels that they won't leave them alone.

For this participant, addiction counselling, marital counselling, spiritual guidance, financial referral to services like MABS, life skills development, and even legal advocacy for the gambler and their family were all part of a normal day in providing assistance in an addiction service.

\section{Perceived Social Measures, Including Policies and Information Provision, to Reduce the Potential for Harm Through Gambling}

Participants identified multiple areas around harmful gambling that need urgent attention. Three major categories of social action at national level emerged: revision and implementation of legislation to regulate gambling; development of services and resources to assist individuals who have been harmed by, or who are at risk of harm, through gambling; and the reduction of shame and stigma through open dialogue and education to increase public awareness of the issue.

Participants unanimously identified the lack of control of the gambling industry as a significant issue which required urgent government attention to legislation. Participants called for an update of outdated legislation from the 1950s and inclusion of a number of topics, including advertisement of gambling opportunities, regulation of technologies used in gambling provision, opening hours, attention to underage gambling, and taxation of gambling. Previous attempts to revise legislation have often derailed. Most recently, a private member's bill, Gambling Control Bill 2018, which is based on the research reported in this paper, had shown the greatest promise for legislative change and potential protection of vulnerable individuals from the harmful effects of gambling. However, this bill stalled after the second reading in the government, even though it uniquely had broad support across political parties.

Because the most recent attempts at legislative reform have not passed, the country still lacks the Social Fund called for in revised legislation. The Social Fund was intended to address critical needs in the country, importantly provision of financial support for treatment, education, and research about harmful gambling, all of which are currently lacking in the country. Further, there is no national framework outlining policy around gambling addiction services, such as those extant for alcohol and drugs. Participants noted that services to help recovering gamblers, as well as their social connections who have experienced harm, needed to be made available across the country so that people in need could access help, particularly where gambling had depleted

The International Journal of Information, Diversity, \& Inclusion, 3(3), 2019

ISSN 2574-3430, jps. library.utoronto.ca/index.php/ijidi/index

DOI: $10.33137 /$ ijidi.v3i3.32962 
family resources. As one family member summed up, "From a regulation point of view within the health service, there is so much mandatory education, particularly in mental health; there needs to be better education with regard to all addictions, not just alcohol."

Participants also called for the development of services targeting harmful gambling, as opposed to mixed addiction treatment. They noted that services themselves should be modified to offer greater aftercare, focused on reintegration of those isolated by harmful gambling into society. As one family member stated: "There should be some focus from the government point of view on counselling as a social service and information in the public domain." A key theme in the development of legislation and social policy was the need for a national approach with equal distribution, implementation and access throughout the country.

Participants also called for an open dialogue about gambling, similar to the openness now surrounding other previously stigmatising social topics, and strategic planning to address harmful gambling. In particular, they demanded public education through increased public awareness of the potential harm of gambling. Examples included advertisements to increase public understanding, as had recently been used to increase awareness of other issues such as mental health. One participant summed up:

[We need] education, just like the ads are there, to replace the ads with education. Because there is a lot of positive education around alcohol, around mental health, around lots of social issues. Use the same techniques, use the same tools, the same methods of advertising or awareness campaigns.

Participants also suggested education about the risks of gambling through the national education curriculum. As one recovering gambler noted, this education was needed in schools, in particular, to help address underage gambling.

\section{Discussion}

This paper reports some of the major findings from a national research study of the social impact of harmful gambling in Ireland. The study stands as a unique piece which is currently being used by legislators, addiction counsellors, national sports programming with children, and elsewhere in the public domain. The study reveals important themes about harmful gambling which remain to be addressed socially.

For gamblers and their families in this study, the information landscape around harmful gambling proved complex, difficult, and often inaccessible. Because harmful gambling is often addressed at a crisis point, both financially and emotionally, participants often found that services requiring financial input could be out of their reach. They might lack funds to support help seeking via addiction services, and the addiction services might be geographically distant, again compromising access. In addition, knowing where to turn in a crisis situation was difficult for participants, particularly given the social stigma and shame attached to gambling addiction and resulting need for secrecy. Participants identified several means of changing the social issues surrounding gambling addiction.

Importantly, recognition of gambling addiction as a public health issue is necessary to enable appropriate strategies for treatment and prevention of problem gambling and the range of social issues that accompany this addiction. Cowlishaw and Kessler (2016) have found that harmful

The International Journal of Information, Diversity, \& Inclusion, 3(3), 2019

ISSN 2574-3430, jps.library.utoronto.ca/index.php/ijidi/index

DOI: $10.33137 /$ ijidi.v3i3.32962 
gambling, which they noted was associated with mental health and psychosocial issues, should be recognised as a public health concern in the UK. To begin addressing harmful gambling, one addiction counsellor in the current study summed up, "The government needs to recognise the enormity of gambling in Ireland." Adams, Raeburn and de Silva (2009) have argued that a public health response, as opposed to a focus on individualised treatment interventions, is essential and provides a wider strategic response to gambling, which should then involve combining efforts internationally. They note that the World Health Organisation (WHO) has yet to identify problem gambling as a public health issue (Adams et al., 2009), and recent searches of the WHO website confirm this missing recognition.

Critically, there are no national health strategies nor policies around harmful gambling, as exist around drugs and alcohol, in Ireland. As a result, a national framework, essential for development of social policies and actions, is missing. Just as the National Drugs Strategy (Department of Tourism, Sport and Recreation, 2008) offered a long-term framework for addressing substance abuse, a working group could do the same for gambling addiction in Ireland. A national tool for assessing gambling addiction, as done for substance addiction, would form part of this work. Such a tool would facilitate working with groups, such as general practitioner doctors (GPs). In addition, a national strategy for service provision that brought together governmental and private organisations could help connect services for those affected by gambling.

Participants further called for open discussion about gambling addiction, and this parallels other movements to remove the shame and stigma attached to issues, such as mental illness, sexual orientation, or suicide. The majority of gamblers do not seek help for reasons including financial resources, embarrassment, stigma, denial, and difficulty with sharing problems (Hodgins \& ElGuebaly, 2000; Petry, 2009; Suurvali, Hodgins, Toneatto, \& Cunningham, 2012). Encouraging open discussion may encourage gamblers at risk or with addiction and others who have been affected by their addiction to come forward for help.

Alongside open discussion, participants wanted education for the public to raise awareness of the risks of gambling. Researchers have called for measures to increase public awareness of problem gambling (Thomas et al., 2017). Research about education around addiction has shown some approaches are more effective than others. For example, Anderson and Baumberg (2006) found that education about alcohol in the classroom increased knowledge about alcohol but had a limited impact on the public's drinking behaviour. The authors suggest that improvement of school-based programmes may increase their effectiveness. Anderson and Baumberg further state that mass media programmes can increase community awareness and facilitate intervention. Groups such as the UK's Department for Culture, Media and Sport (2014), have observed that young people aged 16 to 24 are at the highest risk of problem gambling. They must be helped to understand how to gamble in a socially responsible way, and the gambling industry must work to protect underage youth from exposure to gambling promotions.

The development of regulation around gambling is likely to be the most effective means of reducing harm. According to Anderson and Baumberg (2006), policies that regulate the alcohol market, including taxation and restricted access, are effective and are especially important for protecting young people. Smyth, James, Cullen, and Darker (2015) found that prohibitive legislation around novel psychoactive substances reduced uptake by adolescents in treatment in Ireland. Participants in this study similarly called for regulation of gambling opportunities.

The International Journal of Information, Diversity, \& Inclusion, 3(3), 2019

ISSN 2574-3430, jps.library.utoronto.ca/index.php/ijidi/index

DOI: $10.33137 /$ ijidi.v3i3.32962 


\section{Conclusion}

The social impact of harmful gambling is much wider than just affecting the individuals who gamble. In Ireland, efforts are ongoing to address the problems associated with harmful gambling, and importantly, legislation is urgently needed to move this process forward. The issue is one of speedy action as new technologies, which make legislative and policy development challenging, continue to facilitate and accelerate gambling issues.

\section{Recommendations}

The views of participants in this study are suggestive of multiple reforms and social initiatives in Ireland. Among these are the following, which also appear in the original report for this study (Fulton, 2015; Fulton, 2016) and which have yet to be addressed in Ireland:

- Development of a regulated and responsible gambling environment. Participants advocated revisions to legislation, as well as, importantly, implementation of this legislation to ensure regulation. They further wanted to see the government take social action around addressing harmful gambling in a coordinated fashion. A national gambling strategy and policy would further that goal. Participants also noted the need for a social fund to assist those who had experienced harm from gambling; such a fund has been proposed in recent attempts at legislative reform.

- Improvement of social understanding of gambling. Participants called for an open dialogue about gambling, in which they wanted to increase public awareness of the potential harms associated with gambling. Greater social awareness and openness around discussing gambling addiction would create greater understanding about the problem and reduce social stigma. Participants also believed education was a key component of mitigating the negative impact of harmful gambling.

- Development of addiction services to treat and prevent harmful gambling. Participants demanded a service approach that provided nationwide assistance equally across regions. Currently, there is no national strategy for service provision and no national model for funding services. In addition, participants noted the lack of information around harmful gambling to help those affected by it; greater information and services are needed. Coordination across addiction services, as well as other services to address particular negative outcomes of harmful gambling, would facilitate support for those affected by harmful gambling. Support should be provided for everyone affected by harmful gambling.

- Research about harmful gambling in Ireland. There needs to be additional research about harmful gambling in Ireland and greater funding through national research bodies to support neutral research. The current project has influenced the development of attempts at new legislation; further research will facilitate that endeavour in Ireland.

\section{Acknowledgements}

This paper is part of the study, Playing Social Roulette: The Social Impact of Gambling on

The International Journal of Information, Diversity, \& Inclusion, 3(3), 2019

ISSN 2574-3430, jps. library.utoronto.ca/index.php/ijidi/index

DOI: $10.33137 /$ ijidi.v3i3.32962 
Individuals and Groups in Ireland, which was funded by the Irish Research Council of Ireland's Research Project Grants (RPG) Social Protection Research Innovation Awards (SPRIA) [grant number RPG2013-4], with support from the Department of Social Protection. In addition, this paper was informed by the study, Developments in the Gambling Area, which was funded by the Department of Justice \& Equality, Ireland [grant number V1271].

Thanks go to the funding bodies that supported the completion of this research. The researcher further thanks the reviewers, research assistants, and very importantly, the recovering gamblers, their families and friends, and addiction counsellors who made this paper possible.

\section{Appendix A}

\section{Codebook}

\begin{tabular}{|c|c|c|}
\hline Parent Code & Code & Description \\
\hline \multirow[t]{6}{*}{ 1. Services known } & & $\begin{array}{l}\text { Services to ameliorate the effects of harmful } \\
\text { gambling identified by the participant. }\end{array}$ \\
\hline & Services used & Services, if any, used by the participant. \\
\hline & Service discovery & $\begin{array}{l}\text { Means by which the participant heard about the } \\
\text { services they have identified. }\end{array}$ \\
\hline & Service provider & $\begin{array}{l}\text { Provider of the service (e.g., volunteer counselling } \\
\text { organisation, gambling organisation, etc.) }\end{array}$ \\
\hline & Service provided & $\begin{array}{l}\text { Types of services and supports provided by service } \\
\text { provider identified. }\end{array}$ \\
\hline & $\begin{array}{l}\text { Service } \\
\text { approached }\end{array}$ & $\begin{array}{l}\text { Way in which participant approached service } \\
\text { provider (e.g., alone, with family, with friends, } \\
\text { with others) }\end{array}$ \\
\hline \multirow[t]{4}{*}{ 2. When Help } & & $\begin{array}{l}\text { When the participant decided to ask others for } \\
\text { help. }\end{array}$ \\
\hline & Help reason & Reason for seeking/not seeking help. \\
\hline & $\begin{array}{l}\text { How service } \\
\text { helped }\end{array}$ & $\begin{array}{l}\text { How existing services / organisations helped } \\
\text { participant. }\end{array}$ \\
\hline & $\begin{array}{l}\text { Further help } \\
\text { wanted }\end{array}$ & $\begin{array}{l}\text { Further help participant wanted to see } \\
\text { services/organisations provide. }\end{array}$ \\
\hline
\end{tabular}

The International Journal of Information, Diversity, \& Inclusion, 3(3), 2019

ISSN 2574-3430, jps.library.utoronto.ca/index.php/ijidi/index

DOI: $10.33137 /$ ijidi.v3i3.32962 


\begin{tabular}{|c|c|c|}
\hline Parent Code & Code & Description \\
\hline \multirow[t]{5}{*}{ 3. Services desired } & & $\begin{array}{l}\text { Services participant wanted offered to gamblers } \\
\text { and their families and friends. }\end{array}$ \\
\hline & Major issues & $\begin{array}{l}\text { Major issues that should be addressed identified by } \\
\text { participant }\end{array}$ \\
\hline & Supports needed & $\begin{array}{l}\text { Supports required for those affected by gambling, } \\
\text { as identified by participant (e.g., financial aid, } \\
\text { counselling, particular information, etc.) }\end{array}$ \\
\hline & Prevention & $\begin{array}{l}\text { Preventative measures that should be taken, as } \\
\text { identified by participant. }\end{array}$ \\
\hline & $\begin{array}{l}\text { Support } \\
\text { responsibility }\end{array}$ & $\begin{array}{l}\text { Who should be responsible for setting up and } \\
\text { maintaining supports, as identified by participant. }\end{array}$ \\
\hline
\end{tabular}

\section{References}

Adams, P.J., Raeburn, J., \& de Silva, K. (2009). A question of balance: Prioritizing public health responses to harm from gambling. Addiction, 104(5), 688-691. https://doi.org/10.1111/j.1360-0443.2008.02414.x

Analytical Services Unit. (2010). Northern Ireland gambling prevalence survey 2010. Belfast, Ireland: Department for Social Development.

Anderson, D.J., McGovern, J.P., \& DuPont, R.L. (1999). The origins of the Minnesota Model of addiction treatment: A first person account. Journal of Addictive Diseases, 18(1), 107114. https://doi.org/10.1300/J069v18n01_10

Anderson, P., \& Baumberg, B. (2006). Alcohol in Europe: A public health perspective. London, UK: European Commission. Retrieved from https://ec.europa.eu/health/archive/ph_determinants/life_style/alcohol/documents/ alcohol_europe_en.pdf

Atkinson, R., \& Flint, J. (2001). Accessing hidden and hard-to-reach populations: Snowball research strategies. Social Research Update, 33. Retrieved from http://sru.soc.surrey.ac.uk/index.html

Betting Act of 1931. Number 27. Retrieved from http://www.irishstatutebook.ie/eli/1931/act/27/enacted/en/html

Betting (Amendment) Act of 2015. Number 7. Retrieved from http://www.irishstatutebook.ie/eli/2015/act/7/enacted/en/html

The International Journal of Information, Diversity, \& Inclusion, 3(3), 2019

ISSN 2574-3430, jps.library.utoronto.ca/index.php/ijidi/index

DOI: $10.33137 /$ ijidi.v3i3.32962 
Boyce, C., \& Neale, P. (2006). Conducting in-depth interviews: A guide for designing and conducting in-depth interviews for evaluation input. Watertown, MA: Pathfinder International. Retrieved from

http://www2.pathfinder.org/site/DocServer/m_e_tool_series_indepth_interviews.pdf

Brennan, C. (2016, May 25). Funding is needed 'before it's too late' - There's a surge in gambling addiction in Irish men (and women). The Journal.ie. Retrieved from https: / / www.thejournal.ie/rutland-centre-gambling-2785944-May2016/

Calado, F., \& Griffiths, M.D. (2016). Problem gambling worldwide: An update and systematic review of empirical research (2000-2015). Journal of Behavioral Addictions, 5(4), 592613. https: //doi.org/10.1556/2006.5.2016.073

Castren, S., Perhoniemi, R., Kontto, J., Alho, H., \& Salonen, A.H. (2017). Association between gambling harms and game types: Finnish population study. International Gambling Studies, 18(1), 124-142. https://doi.org/10.1080/14459795.2017.1388830

Cowlishaw, S., \& Kessler, D. (2016). Problem gambling in the UK: Implications for health, psychosocial adjustment and health care utilization. European Addiction Research, 22(2), 90-98. https://doi.org/10.1159/000437260

Data Team (2017, February 9). The world's biggest gamblers. The Economist. Retrieved from https://www.economist.com/graphic-detail/2017/02/09/the-worlds-biggest-gamblers

Department for Culture, Media and Sport. (2014). Gambling protections and controls. London, UK: Department for Culture, Media and Sport. Retrieved from https://www.gov.uk/government/uploads/system/uploads/attachment_data/file/3074 58/Gambling_Protections_and_Controls_.pdf

Department of Health. (2018). Prevalence of drug use and gambling in Ireland and drug use in Northern Ireland 2014/15 drug prevalence study: Gambling results. Belfast, Northern Ireland: Department of Health. Retrieved from https: / /health.gov.ie/wpcontent/uploads/2019/02/Drug-Prevalence-B7-Gambling-Results.pdf

Department of Tourism, Sport \& Recreation. (2008). Building on experience: National drugs strategy 2001-2008. Dublin, Ireland: The Stationary Office. Retrieved from https://www.drugsandalcohol.ie/5187/1/799-750.pdf

Dunne, Flynn \& Sholdis (2017). 2016 Northern Ireland gambling prevalence survey: Main release. Belfast, Northern Ireland: Department for Communities. Retrieved from https: //www.communitiesni.gov.uk/sites/default/files/publications/communities/2016-ni-gambling-prevalencesurvey-main-report.pdf

Economic \& Social Research Institute (2016). Growing up in Ireland project. Retrieved from https://www.esri.ie/growing-up-in-ireland/

European Commission. (2014). Online gambling: Commission recommends principles to ensure effective protection of consumers. Retrieved from http://europa.eu/rapid/pressrelease IP-14-828 en.htm

The International Journal of Information, Diversity, \& Inclusion, 3(3), 2019

ISSN 2574-3430, jps.library.utoronto.ca/index.php/ijidi/index

DOI: $10.33137 /$ ijidi.v3i3.32962 
Fulton, C. (2015). Playing social roulette: The impact of gambling on individuals and society in Ireland. Dublin, Ireland: University College Dublin. Retrieved from https: // researchrepository.ucd.ie/handle/10197/6796

Fulton, C. (2016). Developments in the gambling area. Dublin, Ireland: Department of Justice \& Equality. Retrieved from http://hdl.handle.net/10197/8612

Gambling Control Bill 2018. Number 26. Retrieved from https://data.oireachtas.ie/ie/oireachtas/bill/2018/26/eng/initiated/b2618d.pdf

Gambling Control Bill: General scheme, 2013. Department of Justice \& Equality. Retrieved from http://www.justice.ie/en/JELR/Gambling\%20Control\%20Bill\%202013.pdf/Files/Gamblin g\%20Control\%20Bill\%202013.pdf

Gaming and Lotteries Act 1956. Number 2. Retrieved from http://www.irishstatutebook.ie/eli/1956/act/2/enacted/en/html

Glaser, B.G., \& Strauss, A.L. (1967). The discovery of grounded theory: Strategies for qualitative research. Hawthorne, NY: Aldine.

Guest, G., Namey, E.E., \& Mitchell, M.L. (2013). Collecting qualitative data: A field manual for applied research. Thousand Oaks, CA: SAGE Publications. http://dx.doi.org/10.4135/9781506374680

Hodgins, D.C., \& El-Guebaly, N. (2000). Natural and treatment-assisted recovery from gambling problems: A comparison of resolved and active gamblers. Addiction, 95(5), 777-789.

Institute of Public Health in Ireland. (2010). Developing a population approach to gambling: Health issues. Dublin, Ireland: Institute of Public Health in Ireland. Retrieved from https: / / www.publichealth.ie/files/file/Developing\%20a\%20population\%20approach\%20t o\%20gambling.pdf

Kolb, S.M. (2012). Grounded theory and the constant comparative method: Valid research strategies for educators. Journal of Emerging Trends in Educational Research and Policy Studies, 3(1), 83-86.

Kourgiantakis, T., Saint-Jacques, M., \& Tremblay, J. (2013). Problem gambling and families: A systematic review. Journal of Social Work Practice in the Addictions, 13(4), 353-372. https://doi.org/10.1080/1533256X.2013.838130

Lewis-Beck, M.S., Bryman, A., \& Liao, T.F. (2004). The SAGE encyclopedia of social science research methods. Thousand Oaks, CA: Sage.

Lynch, D., \& O'Reilly, T. (2018). Tony 10: The astonishing story of the postman who gambled $€ 10,000,000 \ldots$ and lost it all. Dublin, Ireland: Gill Books.

Molinaro, S., Benedetti, E., Scalese, M., Bastiani, L., Fortunato, L., Cerrai, S., ... \& Fotiou, A. (2018). Prevalence of youth gambling and potential influence of substance use and other risk factors throughout 33 European countries: First results from the 2015 ESPAD

The International Journal of Information, Diversity, \& Inclusion, 3(3), 2019

ISSN 2574-3430, jps.library.utoronto.ca/index.php/ijidi/index

DOI: $10.33137 /$ ijidi.v3i3.32962 
study. Addiction, 113(10), 1862-1873. https://doi.org/10.1111/add.14275

Mullins, P. (2014). Keeping it simple: A strategic plan 2014 to 2017. Cahir, Ireland: Aiséirí. Retrieved from http://www.aiseiri.ie/Aiseiri_2014-2017_Strategic_Plan\%20.pdf

National Lottery Act 2013, No. 13. (2013). Retrieved from http://www.irishstatutebook.ie/eli/2013/act/13/enacted/en/html

Petry, N.M. (2009). Disordered gambling and its treatment. Cognitive and Behavioral Practice, 16(4), 457-467. https://doi.org/10.1016/j.cbpra.2009.02.005

Ronzitti, S., Soldini, E., Lutri, V., Smith, N., Clerici, M., \& Bowden-Jones, H. (2016). Types of gambling and levels of harm: A UK study to assess severity of presentation in a treatment-seeking population. Journal of Behavioral Addictions, 5(3), 439-447. https://doi.org/10.1556/2006.5.2016.068

Smyth, B.P., James, P., Cullen, W., \& Darker, C.D. (2015) "So prohibition can work?" Changes in use of novel psychoactive substances among adolescents attending a drug and alcohol treatment service following a legislative ban. International Journal of Drug Policy, 26(9) 887-889. https://doi.org/10.1016/j.drugpo.2015.05.021

Suurvali, H., Hodgins, D.C., Toneatto, T., \& Cunningham, J.A. (2012). Hesitation to seek gambling-related treatment among Ontario problem gamblers. Journal of Addiction Medicine, 6(1), 39-49. https://doi.org/10.1097/ADM.0b013e3182307dbb

Svensson, J., \& Romild, U. (2014). Problem gambling features and gendered gambling domains amongst regular gamblers in a Swedish population-based study. Sex Roles, 70(5-6), 240254. https://doi.org/10.1007/s11199-014-0354-z

Thomas, S.L., Randle, M., Bestman, A., Pitt, H., Bowe, S.J., Cowlishaw, S., \& Daube, M. (2017). Public attitudes towards gambling product harm and harm reduction strategies: An online study of 16-88 year olds in Victoria, Australia. Harm Reduction Journal, 14(49). https://doi.org/10.1186/s12954-017-0173-y

Verbiest, T., \& Keuleers, E. (2003). Cross-border gaming: The European regulatory perspective. Gaming Law Review, 7(3), 185-196. http://dx.doi.org/10.1089/109218803766651476

Wardle, H., Moody, A., Spence, S., Orford, J., Volberg, R., Jotangia, D., Griffiths, M., Hussey, D., \& Dobbie, F. (2011). British gambling prevalence survey 2010. Birmingham, UK: Gambling Commission. Retrieved from https://assets.publishing.service.gov.uk/government/uploads/system/uploads/attach ment_data/file/243515/9780108509636.pdf

Crystal Fulton (crystal.fulton@ucd.ie) is an Associate Professor at University College Dublin, Ireland, where she studies the social interactions among people, information, and communication in daily life settings. Her research into the information worlds of people engaged in serious leisure (e.g., genealogists, urban explorers) examines leisure participation and the connections among hobbies, behaviours around information supporting hobby activities, and

The International Journal of Information, Diversity, \& Inclusion, 3(3), 2019

ISSN 2574-3430, jps.library.utoronto.ca/index.php/ijidi/index

DOI: $10.33137 /$ ijidi.v3i3.32962 
impact on individuals, groups, and communities. In particular, her work extends beyond issues of information acquisition to investigate how information is used, shared or hidden, and created in both digital and non-digital environments. Most recently, her research on harmful gambling examined the outcomes of secretive behaviours. She was recently presented with UCD's prestigious Research Impact Case Study Award 2018 for her research on the social impact of harmful gambling. 